\title{
The Economics of the Fifth Generation Cellular Network
}

\section{By: Nir Kshetri}

Kshetri, Nir (2019)." The Economics of the Fifth Generation Cellular Network" IEEE IT Professional 21(2), 77-81.

Made available courtesy of IEEE: https://doi.org/10.1109/MITP.2019.2894240

(C) 2019 IEEE. Personal use of this material is permitted. Permission from IEEE must be obtained for all other uses, in any current or future media, including reprinting/republishing this material for advertising or promotional purposes, creating new collective works, for resale or redistribution to servers or lists, or reuse of any copyrighted component of this work in other works.

\begin{abstract}
:
Fifth generation cellular services are expected to rapidly take off in the next few years. In combination with other advanced technologies, they are likely to transform key economic activities.
\end{abstract}

Keywords: 5G mobile communication | economics | couplings | artificial intelligence | companies | cellular networks

\section{Article:}

Fifth generation $(5 \mathrm{G})$ cellular services were first deployed on a trial basis in the 2018 Winter Olympics in South Korea. ${ }^{1}$ Since then, some telecommunications operators have commercially launched 5G services. In May 2018, Qatar's Ooredoo reported that it launched what it referred to as the world's first $5 \mathrm{G}$ cellular services on a limited basis (https://venturebeat.com/2018/05/14/worlds-first-commercial-5g-network-launches-in-qatar/). In June 2018, the Finnish telecommunications provider Elisa reported that it launched 5G networks in Tampere, Finland, and Tallinn, Estonia. The company noted that it was already selling 5G subscriptions.

In the U.S., by December 2018, AT\&T's 5G services had been offered in 12 U.S. cities. The offers were limited to customers with $5 \mathrm{G}$ devices. Verizon reported that it launched a commercial 5G network in some U.S. cities. ${ }^{2}$ As of January 2019, T-Mobile had deployed 5G network equipment in 30 U.S. cities. However, it had not offered commercial $5 \mathrm{G}$ services. ${ }^{3}$

$5 \mathrm{G}$ services are expected to rapidly take off in the next few years. According to Swedish networking and telecommunications company Ericsson, $20 \%$ of mobile data traffic worldwide will be on 5G networks by 2023 (https://www.fiercewireless.com/wireless/china-leads-iotdeployments-while-north-america-leads-5g-ericsson). The value-creating potential of $5 \mathrm{G}$ has significant implications for many industries. Many companies are developing products and services that would help enrich the global $5 \mathrm{G}$ ecosystem. ${ }^{1}$ 
According to the cellphone trade group GSMA, there will be 1.2 billion $5 \mathrm{G}$ connections worldwide by 2025 (https://rakuten.today/blog/10-things-learned-mobile-world-congress2018.html). Asia and the U.S. are expected to take the lead (www.cnbc.com/2018/03/07/chinahas-the-edge-in-the-war-for-5g-us-and-eu-could-fall-behind.html). Among Asian economies, China is likely to experience the fastest $5 \mathrm{G}$ growth. A report of the consultancy company EY indicated that China will have 576 million $5 \mathrm{G}$ users, more than $40 \%$ of the global total by 2025 (http://www.chinadaily.com.cn/a/201806/28/WS5b34486fa3103349141df708.html). Among European economies, the U.K. is likely to take a lead (https://5g.co.uk/news/uk-networks-couldbeat-europe-5g-launch/4456/). It is estimated that $90 \%$ of the U.K. population will be covered with 5G by 2027 (https://www.sciencedirect.com/science/article/pii/S0308596117302781).

5G cellular networks have many attractive features, such as lower latency, higher bandwidth, and higher degree of reliability. $5 \mathrm{G}$ networks utilize millimeter wave, which is usually considered to be the range of wavelengths from 10 to $1 \mathrm{~mm}$ (https://ethw.org/Millimeter_Waves). Compared to the frequency spectrum used by previous wireless network technologies, the amount of bandwidth available at millimeter wave frequencies is significantly higher. Millimeter wave frequencies thus provide the massive bandwidth. This is especially important to transmit data created by a large number of Internet-of-Things (IoT) devices. In the 2018 Winter Olympics, South Korean telecommunications company Korea Telecom's peak 5G network speed was up to $3.5 \mathrm{~GB} / \mathrm{s}$ on Samsung tablets (www.fiercewireless.com $/ 5 \mathrm{~g} / \mathrm{kt}$-s-millimeter-wave- $5 \mathrm{~g}$-networktransmitted-3-800-tb-data-during-winter-olympics). In January 2018, South Korea's average mobile broadband download speed (which was the fourth highest in the world) was $133.05 \mathrm{Mb} / \mathrm{s}$. This means that peak speeds in 5G networks during the 2018 Winter Olympics were more than 26 times the country's mobile broadband download speed.

4G/ Long-term evolution (LTE) networks have relatively high latency, which varies between 30 and 100 milliseconds (MS) (https:/Www.ecnmag.com/article/2018/08/breaking-psychologicalbarrier-autonomous-vehicle-adoption). $5 \mathrm{G}$ networks get closer to the user in terms of antennas, which reduces the latency. This feature is especially valuable and useful for services such as remote robotic surgery and autonomous vehicles (AVs).

Let us look at the cost-benefit tradeoffs of 5G networks. On the cost side, 5G networks, platforms, and devices certainly require high investments. According to technology advisory firm Xona Partners, in order to deliver a coverage comparable to existing 4G/LTE networks, 5G would need six times as much investment. The higher investment is needed because $5 \mathrm{G}$ networks improve performance by getting closer to the user in terms of antennas and computing power. ${ }^{4}$ There are, however, important economic benefits associated with 5G networks. 5G networks enable a high data transfer rate. From an operator's standpoint, 5G networks have lower cost per bit of data compared to 4G networks (https://www.v3.co.uk/v3-uk/news/3062204/qualcomm-5gmobile-broadband-will-launch-in-the-us-by-april-2019).

$5 \mathrm{G}$ is likely to stimulate economic activities in a number of areas. For instance, for the AV industry, high latency is a concern with the 4G LTE networks (https://www.ecnmag.com/article/2018/08/breaking-psychological-barrier-autonomous-vehicleadoption) (see Table 1). In order to maintain awareness of the surroundings and safely steer 
through traffic with vehicle-to-everything communications, AVs need a 1 MS latency. With 5G networks, an autonomous car will be able to hit the brakes and stop it within 1 in, compared to $4.6 \mathrm{ft}$ it takes with 4G (https://www.cta.tech/News/i3/Articles/2017/July-August/The-Promiseof-5G.aspx).

Likewise, $5 \mathrm{G}$ will create a rich e-commerce ecosystem and a better customer experience. Especially $5 \mathrm{G}$ networks in combination with other advanced technologies such as the IoT, machine learning (ML), artificial intelligence (AI), virtual reality, augmented reality, and blockchain are bound to transform e-commerce and other economic activities. ${ }^{5}$

Table 1. Predicted economic impacts of $5 \mathrm{G}$ cellular networks in major economies.

\begin{tabular}{|c|c|c|c|}
\hline Economy & Forecast year & Study conducted by & Economic impact \\
\hline China & 2025 & $\begin{array}{l}\text { China Academy of } \\
\text { Information and } \\
\text { Communications } \\
\text { Technology }\end{array}$ & $\begin{array}{l}\text { 5G market: U.S. } \$ 167 \text { billion }(3.2 \% \text { of GDP) } \\
\text { (https://variety.com/2017/digital/asia/china-to-become-world- } \\
\text { leader-in-5g-political-controls-damp-content-industry- } \\
\underline{\underline{1202624028 /) .}}\end{array}$ \\
\hline India & 2035 & $\begin{array}{l}\text { A committee on India's } \\
5 \mathrm{G} \text { road map }\end{array}$ & $\begin{array}{l}\text { Cumulative economic impact U.S. \$ } 1 \text { trillion } \\
\text { (https://www.moneycontrol.com/news/business/panel-on-5g- } \\
\text { road-map-sees-1-trillion-impact-on-economy-2875251.html). }\end{array}$ \\
\hline The U.K. & 2030 & King's College London & $\begin{array}{l}\text { U.S. \$226 billion } \\
\text { (https://www.kcl.ac.uk/newsevents/news/newsrecords/2018/02- } \\
\text { February/British-universities-debut-world's-first-5G-end-to- } \\
\text { end-network-at-Mobile-World-Congress.aspx). }\end{array}$ \\
\hline The U.S. & 2024 & Accenture & $\begin{array}{l}\text { Boost GDP by U.S. } \$ 500 \text { billion, create } 3 \text { million new jobs } \\
\text { (Amine et al., 2017). }{ }^{8}\end{array}$ \\
\hline World & 2035 & Qualcomm & $\begin{array}{l}\text { 5G value chain will create } 22 \text { million jobs, generate U.S. } \$ 3.5 \\
\text { trillion in revenue, full economic benefit: U.S. } \$ 12 \text { trillion } \\
\text { (https://www.qualcomm.com/invention } / 5 \mathrm{~g} / \text { economy). }\end{array}$ \\
\hline
\end{tabular}

\section{ECONOMIC IMPACTS OF 5G CELLULAR NETWORKS IN MAJOR ECONOMIES}

Among mature economies and large and developed countries, McKinsey Global Institute's analysis of data indicated that the Internet accounted for $21 \%$ of the GDP growth during 20062010. It accounted for $3.4 \%$ of the GDP in 2009, which was more than communication, utilities, agriculture and mining. ${ }^{6}$ These benefits can be further improved with $5 \mathrm{G}$ networks. Qualcomm predicted that by 2035 , the $5 \mathrm{G}$ value chain will create as many as 22 million jobs worldwide and generate U.S. \$3.5 trillion in revenue worldwide (http://www.newschinamag.com/newschina/print.do?article id=4133\&section id=5\&magazine $\underline{\mathrm{id}=33}$ ). By that time, 5G's full economic benefit will amount U.S. \$12 trillion (https://www.qualcomm.com/invention/5g/economy). Similar findings have been reported by studies conducted in other major economies. Table 1 presents the predicted economic impacts of $5 \mathrm{G}$ cellular networks in major economies.

A number of mechanisms can contribute to the ability of $5 \mathrm{G}$ to stimulate economic activities. First, lower generation networks are mainly used to connect cellular phones. 5G networks are used to connect a wide range of devices such as home appliances, industrial automation equipment, cars, laptops, and televisions (https://www.extremetech.com/mobile/271665-5gstandard-finalized-for-standalone-deployments). 
5G networks support significantly larger numbers of devices per cell compared to previous generations. A working party developing $5 \mathrm{G}$ standards has specified at least one million devices per square kilometer (https://www.itu.int/md/R15-SG05-C-0040/en).

It is possible to optimize each slice in order to provide the required resources and quality of service (QoS) in terms of latency, data flow rate (throughput), capacity, and coverage (https://www.cablelabs.com/network-slicing-building-next-generation-wireless-networks/). 5G providers, thus, can address the difficulties with the one-size-fits-all nature of the 4G/LTE networks in which all customers are likely to receive the same types of services irrespective of the needs. For instance, $5 \mathrm{G}$ service providers can provide different types of networks with different levels of bandwidth, security, or latency for diverse applications, such as smart homes, smart workplaces, or smart cities.

Despite tremendous economic benefits, big data's use has not been as widespread as many had expected. According to IDC, only $0.5 \%$ of the world's information was analyzed in 2012. More recent studies have indicated that $5 \%$ of created data is actually utilized. Currently it is not possible to transmit the data to a place where it can be processed and analyzed. Data creation is growing more than twice as fast as bandwidth (www.ibm.com/blogs/research/2017/02/bringingedge-computing-to-life). $5 \mathrm{G}$ networks can address this bottleneck by increasing data transmission rates. Estimates suggest that $5 \mathrm{G}$ will make it possible to utilize $35 \%$ of digital data. ${ }^{7}$

In 5G, using software-defined networking, a single network can provide a variety of heterogeneous services or "slices." Network operators can provide specific capabilities for varying use cases (https://www.cio.com/article/3234373/networking/5g-network-slicing-what-isit-and-why-you-should-care.html). Indeed, it is argued that $5 \mathrm{G}$ networks are less about speed and more about capacity and the ability to provide targeted services for various use cases that are most in need (https://www.ft.com/content/1279a1e8-8110-11e8-af48-190d103e32a4). Each slice can be managed independently. Network slicing can reduce operating expense (OPEX). Network slicing can promote flexibility, scalability, and efficiency from the resource management perspective. Operators can analyze each slice's OPEX and revenue independently (https://www.cablelabs.com/network-slicing-building-next-generation-wireless-networks/). They can, thus, increase revenue and profitability.

It is possible to optimize each slice in order to provide the required resources and QoS in terms of latency, data flow rate (throughput), capacity, and coverage (https://www.cablelabs.com/network-slicing-building-next-generation-wireless-networks/). 5G providers, thus, can address the difficulties with the one-size-fits-all nature of the 4G/LTE networks in which all customers are likely to receive the same types of services irrespective of the needs. For instance, 5G providers can offer different types of networks with different levels of bandwidth, security, or latency for diverse applications, such as smart homes, smart workplaces, or smart cities.

\section{ECONOMIC LINKAGES AND THE DIFFUSION OF 5G NETWORKS}


The success of $5 \mathrm{G}$ networks hinges on the development of related industries. Development and diffusion of 5G are tightly linked to the forward linkages (demand), backward linkages (supply), and horizontal or intersectoral linkages. Table 2 presents the roles of linkage mechanisms.

Table 2. Roles of linkage mechanisms in the development of 5G networks.

\begin{tabular}{|l|l|l|}
\hline Linkage mechanism & Explanation & Some examples \\
\hline Forward linkages & $\begin{array}{l}\text { The 5G services are used as the raw material of } \\
\text { another industry. New industries/businesses are formed } \\
\text { or existing industries grow faster. }\end{array}$ & $\begin{array}{l}\text { 5G will stimulate the growth of the } \\
\text { AV industry (e.g., South Korea). }\end{array}$ \\
\hline Backward linkages & $\begin{array}{l}\text { Industries or businesses that support 5G by creating } \\
\text { various forms of positive externalities. }\end{array}$ & $\begin{array}{l}\text { Costs and availability of labor, } \\
\text { equipment, and other factors affect } \\
\text { 5G development (e.g., China). }\end{array}$ \\
\hline $\begin{array}{l}\text { Horizontal or } \\
\text { intersectional linkages }\end{array}$ & $\begin{array}{l}\text { Interaction between interdependent firms in two or } \\
\text { more economic sectors: Actions taken by 5G network } \\
\text { providers in partnership with other sectors outside 5G. }\end{array}$ & $\begin{array}{l}\text { The development of 5G networks } \\
\text { facilitated by related technological } \\
\text { sectors such as AI and blockchain. }\end{array}$ \\
\hline
\end{tabular}

Forward Linkages

The strength of forward linkages between 5G networks and the rest of the economy is a critical factor. The demand of $5 \mathrm{G}$ is higher in economies that focus on advanced use cases that require reliable, fast, and low latency networks. For example, the AV industry produces forward linkages. In South Korea, Hyundai and Korea Telecom developed 5G-equipped autonomous buses for the 2018 Winter Olympics. Hyundai's aim is to start selling self-driving vehicles by 2021. Hyundai is also expected to launch self-driving taxis. Korea Telecom's self-driving bus was referred to as the "5G Bus." They operated in the town of Gangneung, where ice hockey and skating matches took place.

\section{Backward Linkages}

The development of industries that supply various ingredients needed for $5 \mathrm{G}$ helps to foster backward linkages. Low labor costs and other inputs are an important source of backward linkage. In this regard, China has a cost advantage. Deloitte estimated that the equipment necessary to develop a wireless network capacity cost about $35 \%$ less in China than in the U.S. According to Deloitte, from 2015 until the mid-2018, China spent U.S. \$24 billion more than the U.S. in 5G technology. China built 350000 new cell sites during this period compared to fewer than 30000 in the U.S. ${ }^{9}$

More importantly, 5G-related R\&D activities can provide strong backward linkages. As of March 2018, China accounted for 32\% of the world's 5G standard contributions. By then, it had submitted over 8700 related documents to the third generation partnership project, which is a collaboration between groups of telecommunications standards associations (https://technode.com/2018/03/30/5g/).

Local handset and device manufactures also provide backward linkages. China-based technology companies ZTE and Huawei announced that they would release 5G in 2019. South Korean device maker Samsung released its 5G tablet in early 2018. In the 2018 Winter Olympics, Samsung's 5G-equipped tablets allowed viewers to switch among multiple cameras placed along 
the cross-country skiing route so they could track an athlete's real-time location on a threedimensional map of the entire skiing course. ${ }^{1}$

Horizontal or Intersectoral Linkages

An intersectoral linkage is said to exist between two economic sectors if activities in one can provide a stimulus to another. Higher benefits can be derived by combining $5 \mathrm{G}$ with other technologies such as big data and AI. For instance, network operators need to use advanced analytics, ML and AI in order to manage service quality and predict failures. ${ }^{10}$

Some mobile operators have taken initiatives in this direction. China Mobile announced its plan to enhance $5 \mathrm{G}$ 's operational efficiency with AI (http://www.chinadaily.com.cn/a/201806/28/WS5b34486fa3103349141df708.html). Another telecom company, i.e., China Unicom and Chinese tech conglomerate Tencent, have established a joint laboratory to focus on R\&D efforts related to key technologies and business applications. They include edge computing, network slicing, and high-accuracy positioning services (http://usa.chinadaily.com.cn/a/201806/29/WS5b3575fda3103349141dfa05.html). Likewise, China Unicom's laboratory with the Chinese search provider Baidu aims to integrate AI with 5G. The two companies have placed special emphasis on the internet of vehicles and big data (http://usa.chinadaily.com.cn/a/201806/29/WS5b3575fda3103349141dfa05.html).

\section{CONCLUDING COMMENTS}

From the perspective of data transmission, $5 \mathrm{G}$ networks perform significantly better than the previous generations both in terms of capacity as well as cost effectiveness. 5G is, thus, a key missing link in the utilization of relevant data in order to make informed decisions based on data. The diffusion of 5G cellular networks is likely to lead to major economic and social impacts. Specifically, 5G, in combination with other advanced technologies, is bound to transform many industries and fundamentally alter consumption patterns. For instance, blockchain's technical potential as a means of creating trust, transparency, and accountability can be realized by using $5 \mathrm{G}$ networks to provide reliable data.

The benefits of $5 \mathrm{G}$ can be enhanced by giving more attention to the economics of linkage effects, including the processes by which $5 \mathrm{G}$ can be combined with other technologies to deliver higher value to the end users. Many small developing countries lack linkages, as well as necessary resources and capabilities, that are essential to respond to the needs of the $5 \mathrm{G}$ era. Full potential of this technology cannot be realized without developing capabilities in areas such as advanced analytics, AI, and ML.

\section{REFERENCES}

1. N. Kshetri, D. Rojas, "The 2018 Winter Olympics: A showcase of technological advancement", IEEE IT Professional, vol. 20, no. 2, pp. 19-25, Mar./Apr. 2018.

2. "AT\&T launches 5G network: What you need to know as Verizon T-Mobile Sprint race to catch up", 2018, [online] Available: 
https://www.usatoday.com/story/tech/columnist/komando/2018/12/27/att-launches-5-g-networkwhat-you-need-know-verizon-sprint-t-mobile/2386190002/.

3. "T-Mobile quietly confirms $5 \mathrm{~g}$ network in 30 cities", 2018, [online] Available:

https://www.lightreading.com/mobile/5g/t-mobile-quietly-confirms-5g-network-in-30-cities/d/did/748791.

4. P. Lyons, F. Rayal, "5G mobile is nearly here- but we should share networks to make it affordable", 2018, [online] Available: https://www.weforum.org/agenda/2018/08/5g-mobile-isnearly-here-share-networks-to-make-affordable/.

5. N. Kshetri, "5G in E-commerce activities", IEEE IT Professional, vol. 20, no. 4, pp. 73-77, Jul./Aug. 2018.

6. J. Manyika, C. Roxburgh, "The great transformer: The impact of the Internet on economic growth and prosperity" in, New York, NY, USA, Oct. 2011.

7. J. Davis, "5G is coming in 2019: Here's what hospitals should know about it", 2017, [online] Available: https://www.healthcareitnews.com/news/5g-coming-2019-heres-what-hospitalsshould-know-about-it.

8. M. A. Amine et al., "How 5G can help municipalities become vibrant smart cities", 2017, [online] Available: https://newsroom.accenture.com/content/1101/files/Accenture 5GMunicipalities-Become-Smart-Cities.pdf.

9. A. Kharpal, "China has outspent the US by $\$ \$ 24$ billion in 5G technology since 2015 catching up could be hard", 2018, [online] Available: https://www.cnbc.com/2018/08/07/china-outspentus-by-24-billion-in-5g-technology-since-2015.html.

10. P. Ostiguy, "What's the plan for command \& control of 5G networks?", 2018, [online] Available: https://www.lightreading.com/mobile/5g/whats-the-plan-for-command-and-controlof-5g-networks-/a/d-id/745406. 